\title{
The Rule of Persuasion in the Marketing Process
}

\author{
Francesco Greco* \\ University of Niccolò Cusano, Italy
}

Submission: June 01, 2018; Published: September 27, 2018

*Corresponding author: Francesco Greco, University of Niccolò Cusano, Italy, Email: grecofrancesco69@gmail.com

\begin{abstract}
The main goal of the article is to bring forward the idea of abandon definitively the concept that all purchases are rational, with reference to some objective norm or to some universal law. Sometimes the wishes and choices of purchase of persons are predictable, sometimes are not. If the field of consumption was dominated by the laws of rationality, we would not need to have recourse to the cognitive analysis or the paradox. The people, either as individual consumers, that as corporate decision makers, express, in their behavior, the entire human nature, in which replaces, often, a slope of irrationality. Transferring these concepts in marketing, it can be argued that if it is possible to understand what causes voltage to a subject, you will be able to identify potential levers of purchasing, as this voltage is produced by stimuli that can be addressed in the search for a product or a service.
\end{abstract}

Keywords: Advertising communication; Change cognitive behavioral; Theory of reasoned action; Principle of coherence; Cognitive dissonance theory of cognitive response; Competitive strategies on brand; Paradox of Allais and the theory of the Prospect by Tversky and Kahneman

\section{Introduction}

The study of consumers is a challenge that always affects the marketing. Identify and satisfy his desires, understand how he perceives and considers the messages of the company is of vital importance for businesses [1]. To understand the consumer, it is necessary to analyses the reality that surrounds them and understand how they relate to it. In recent years we have witnessed profound changes that have affected society and its natural balance. The economic crisis and the dynamics of the web have distorted the values of society and consequently the marketing is trying to redefine the boundaries of their own discipline to respond in a consistent and effective manner to new scenarios. The successful policies of the past must be rebuilding in today's reality and operating manuals of marketing must therefore adapt to the new market dynamics [2].

Every day we are surrounded by symbols, images and messages of which only a very small minority able to go beyond our perceptual barriers and arouse our interest. This surplus of culture, joined to the fragmentation of the experience and of the very sense of self, understood as the membership of an individual to more social spheres and meaning (relegated not to a single style of life or to a single identity) reveals one of the most relevant concepts that distinguish the company today: the problem of identity building due to fragmentation of the individual. The marketing must then take note of these phenomena and offer individuals/consumers, what can help them to express their own identity.

Morace says that "the identity of each one and its relative expression, you play and then through a delicate balance between membership of a collective heritage (the community culture of origin, the family group) and expression of an individual character which however tends to distinguish personal. ${ }^{1 ~ " . ~ C o n s u m e r s ~ t o d a y ~}$ are looking for in products the affirmation of identity ${ }^{2}$ and at the same time, the brand, through their positioning seek to define their own identity, as a set of specific values to offer to consumers [3].

In a communicative context articulated and complex, characterized by a media crowding becomes increasingly difficult to persuade. The large amount of information that comes to our senses requires an inevitable selection. One of the main requirements of the communicators and experts of marketing is, in fact, be able to attract the attention and to arouse interest of a public that is increasingly aware. The attention of the public is not an unlimited resource. It is simply not enough to put on the stage a product or a message because this is perceived [4]. Our way of processing the information, in fact, responds to the principle of maximum energy savings ${ }^{3}$. Generally, the information 
more easily perceived are those adapted- if those who agree with our stereotypes, those that coincide with a scheme already consolidated in our memory. This selective mechanism is only as strong as lower is the degree of involvement in the selection or in the evaluation of a specific message.

To make it even more complex the work of communicators is the awareness that the message received is not always properly understood and interpreted. Various studies have shown that not always the intentions of the communicator are educated, and including, from your reference target. This applies especially if your target group has characteristics such as for example children [5]. A research carried out several years ago shows that only $50 \%$ of preschool children can understand at least half of the television material shown, despite such material was considered appropriate for children. ${ }^{4}$

The same problem is also seen in the programming process. The ratio between the product object of the message and what should be remembered is not linear and direct. The risk of who is responsible for creating competitive traps is not only to make it incomprehensible the sense of communication but also to facilitate the storage of some aspects less imported of the message itself. How many times did you have stored a nice publicity or abutment fun or an aspect which is particularly effective in one spot without remind you of the most important aspect of the message: the product?

The present chapter has as objective to analyze the reactions when you want to get something from someone, sometimes it is necessary to adopt paradoxical behavior; this incipit not surprising because the paradox recurs frequently in defining the operation of marketing, especially in the context of the relations between the supplier and the customer [6].

Transferring these concepts in the arena of marketing, it can be argued that if it is possible to understand what causes voltage to a subject, you will be able to identify potential levers of purchasing, as this voltage is produced by stimuli that can be addressed in the search for a product or a service. Therefore, research and study of latent needs or poorly satisfied allows to open great opportunities to marketing [7]. Also, in the field of business to business, if you can understand what causes voltage to an enterprise buyer, you will be able to identify the motivational levers of the acquiring company, and accordingly adjust the offer.

In the more advanced models of marketing, the process of the purchase must necessarily be compared with that of motivation. And that is what are the factors that drive the individual to purchase? The theory of motivation sees as a motivating unit base, the voltage again. The pulses voltage generators engage on member of imbalance perceived and create a thrust to the resolution of the problem through the achievement of states of equilibrium [8]. The pulse becomes motive of purchase in the moment when the perception that the purchase can become the instrument of resolving the problem.

Sometimes the wishes and choices of purchase of persons are predictable, sometimes are not. If the field of consumption was dominated by the laws of rationality, we would not need to have recourse to the cognitive analysis or the paradox [9]. The people, either as individual consumers, that as corporate decision makers, express, in their behavior, the entire human nature, in which replaces, often, a slope of irrationality.

\section{Types of change and advertising communication}

Before entering the merits of the technical aspects need to dwell briefly on the various functions that has the advertising communication. The simplest of the objectives of advertising communication is to make available the information and try to determine a cognitive change [10]. The cognitive change does not necessarily entail a change of behavioral consists in the mere transmission of information.

In this case the main purpose of the process is persuasive is to create awareness and knowledge, providing only adequate information. A different objective is the change of action, namely to induce a certain number of people to perform a specific action within a specified period. This is a change more difficult to achieve with respect to the previous one. So that there is a change of action is not enough understanding of the message and the receipt of information: we need to provide adequate information and effective grounds on which individuals will be forced to perform a specific action [11].

Even more complex is the declared objective of behavioral change that consists in inducing a modification permanent of the behaviour of a group of people that have or less an attitude- chin favorable toward it. It is a process very complex that invokes the report (non-linear) between attitude and behavior [12]. One of the main difficulties in the implementation of the communication process effectively persuasive is precisely since the change of an attitude toward a practice does not necessarily correspond to a change of behaviour. The information on some products or situations are not enough to determine a behaviour.

Just think of all those times in which was not free respect their own attitudes for fear of social evaluation. In this case we have attitudes that do not match the behaviour and conversely. The theory of reasoned action of Fishbein and Ajzen ${ }^{5}$ indicates, in fact, that the behaviour of a person depends, apart from the attitude (i.e. from the evaluation of the attributes of a particular product and the degree of probability that these attributes characterize that product or that particular situation) but also by other variables such as social pressure, individual expectations of the results of an action, the value attributed to these results

${ }^{4}$ (Freidlander et al. 1974).

${ }^{5}$ (Ajzen and Fishbein 1980, Fishbein and Ajzen 1975) 
[13]. According to this model to speak of persuasion and of changing attitudes is necessary to assess the social value that has for individuals the intention to act a behaviour. In everyday life most of our intentions are so close to not be comparable to a slow process and aware, nor based on a careful analysis of the costs and benefits as described by explanatory models such as that of the theory of reasoned action [14].

This theory, in fact, offers us an idea of man almost exclusively rational, characterized by decision-making conscious and rational, as the traditional vision of man promoted by the theorists of Human information processing. In this case the persuasion depends solely by a rigorous process of rational assessment of the attributes of their value and the pressure of the social norm. To this criticism the act a behaviour: the perception of the audit. Finally, a last is more difficult purpose of persuasive communication is proMove a change of values [15].

This is to modify the values and opinions deeply rooted that some individuals have with respect to certain subjects and situations (e.g. campaigns for the limitation of births and those against racial prejudices) [16]. In relation to these objectives the communication not only takes on a character of the essentialism for the sharing of information and news but contributes to the establishment and the maintenance of the company.

\section{Beyond the informative function of advertising com- munication}

In the absence of precise institutional references in the guide of the behaviours and lifestyles communications media has assumed an important role also in the influence and contribute to determine the construction of his own image. ${ }^{6}$ Today the common sense is always more guided by media indications more than from the value of the intergenerational teaching or friendship [17]. The individual as an active subject that treats and information in an autonomous way and still in a context of meanings existing personal and acts based on raw material and information offered by the media. It is by now consolidated the conviction that the interest to acquire information, as well as the exposure, the perception and storage of a message occur according to processes selective for which, "...the components of the audience tend to expose themselves to information congenial to their attitudes and to avoid messages that are instead different". ${ }^{\text {? }}$

In fact, the theme of persuasion has assumed for the first time, in relation to the dynamics of consumption, a significant valence with the advent of advertising communication. This process is exasperated with the exponential growth of the competitiveness and the crowding of the market offers. While in a market of the first and of the second industrialization there was space to not overlap the specific usefulness and functions of products and services in the current phase, especially in the market's tributaries, the objective value of products requires a greater effort of proactive in processes of influencing consumers and then in the role of advertising [18]. The persuasive communication, in a first time characterized by the value of the rationality of the useful and convenience of today must rely on motivational levers symbolic, social and aesthetic, varying not only the variables which characterizes the persuasive processes and their effect on the decision-making processes but also the modes of study and research.

\section{Change aware or occult persuasion: The persuasive ad- vertising}

In previous years to the development of the means of mass communication attention to the theme of persuasion and decision-making processes was born by research and by political surveys during election campaigns us [19]. The possibility of influencing the decision to act a purchase behaviour or to vote beyond the awareness of rationality, correctness, truthfulness and values of the arguments is the basis of the concerns relating to the relationship between technical persuasive and decisions.

A concern still alive today as testified by the "fears" toward a communication does not immediately identifiable and controllable. As you can see from the field studies the advent of radio and television have stimulated the research on persuasive mechanisms and on the effect that these processes could have on the weakest Groups or "suggestion" as for example children [20]. We are in the historical period in which research on techniques persuasive visible has stimulated debate on the theme of the mechanisms of influencing the occult and on subliminal processes. That of Subliminal Perception, i.e. a perception that occurs under the threshold (sub limed) of sensitivity, is a that begins in 1884 with a study that demonstrates that it is possible to perceive small differences of pressure on the skin without having the awareness of sensation..$^{89}$

Studies that have originated at the end of the nineteenth century and the beginning of the next century and relating to the value of the absolute threshold of perception (absolute value noticeable) and the differential threshold are at the basis of the debate on the communication on subliminal processes. In the first period of affirmation of the research on consumption and on persuasion attention, in fact, was directed to the cognitive processes controlled, which provide for the making of a choice through a series of steps to very precise: research careful of information, evaluation of alternatives, the evaluation of the weights and the values recognized to the individual attributes of the products or services and finally the analysis after purchase and the assessment of the degree of satisfaction of needs [21].

${ }^{6}$ Mitra, 1999, pp. 67,68), in the construction and definition of their values

${ }^{7}$ (Tan, Fujioka, Bautista, Maldonado, Tan, Wright, 2000; Kang, Perry, Kang (1999) (Klapper, 1963, pp. 245).

${ }^{8}$ (Concept already problematic for the arbitrariness of the point in which to place The threshold: see Lupker, 1986)

${ }^{9}$ (Peirce, Jastrow, 1884). 


\section{Psychology and Behavioral Science International Journal}

The implicit assumption that respected in this way to study the relationship between persuasion and decision was that the purchasing behaviour could be captured, explained by a comprehensive model or from a "Great theory".

\section{From the value of persuasive the utility to the symbolic attraction}

One of these theories on decision-making processes saw the behaviour as exclusively guided by principles explaining the usefulness and the logical explanations of the processes [22]. According to this principle the individual is seen as a subject capable of taking decisions based on careful and rational information search, trying to obtain the maximum benefit from it (individual or social) with the minimum expenditure of energy. This stability was connected to a principle of consistency which linked the individual to be consistent with the values and principles that had internalized and that had to be able to translate into behaviour congruent, even in the absence of a social context that can support these value models [23].

The cultural context of the company post-modern deeply modify this way of understanding the human being and its decisionmaking processes. The postmodernism indeed surrenders to the idea of a subject and a stable conscience, auto governed, anchored through the reason for a universal objective rationality, able to contain the influences manipulators and persuasive processes. The postmodernism chooses to "accept the radical specificity of the subject, his with absence to anchorages to rationality".

This contribution appears increasingly unsatisfactory for various reasons. In the first place, is questionable the allegation that the study psychological processes persuasive on decision of consumers essentially concerns the mechanism by which the operator of marketing aims to influence the attitudes and behaviour of the consumer [24]. The literature presents prescriptive models of decision aimed to define the best way to take a decision in accordance with the requirements of functionality and own sequencing of a rational process, but it is mostly models based on allegations of rationality and human being rather unrealistic.

Herbert Simon $(1957,1979)$, which in 1978 won the Nobel Prize for his work on decision-making, replaced the classic model with that of Limited rationality or procedural: also tends to define the procedures to identify the best possible decision, but bearing in mind the subjectivity, the limits and the processes of influencing that characterize the final decision [25]. The theory of Limited rationality, according to which the decision-making processes are processes of research and not processes of deductive reasoning, has made a point of reference for subsequent studies concerned to develop descriptive models of the decision-making process, but remains however the constant reference to the sequence of the phases in which the decision-making process is divided (research of information processing alternatives, evaluation and choice), more prescriptive that descriptive, unrealistic compared to the actual dynamics in act. In the current view and post- modern consumer/spectator of messages is meaningless to speak of "behaviour" of the consumer as if there existed a standard consumer that behaves in a manner known and predictable, according to the laws studied by a psychology substantially individualistic?

On the other hand, according to the already cited Simon (1957), if of rationality it is necessary to speak, this is nevertheless always "limited" by the difficulties and the costs of research information in the outside world and from the limits purely internal, such as the difficulty of cognitive processing of information, memory limits and attention [26]. The psychological knowledge of human phenomenon is increasingly the provisional outcome of the study and the research done with people who live the complexity of their quota's contexts: a global knowledge and contextualized, more appropriate to describe and to understand, explain and interpret how and why people and groups think and feel and act in the consumer society in which we live.

\section{The main theories of reference on persuasion}

The main theories of reference on persuasion Transmit thoughts and induce behaviour is only a small facet of a phenomenon much richer and more complex, on which rests the construction of our vision of the world and - one might almost say-the creation of the world in which we live. This is a facet of the way of understanding the relationship between communication, advertising and behaviour that still seems too tied to old theories, more inspired by a positivist vision of man in the modern age [27].

The hypodermic theory: In the study of persuasive processes and different communication scholars have tried to enclose in a sort of modelling, agents or the key factors involved in the persuasive communication. Already in the first postwar years the attention throughout the United States to the processes of analysis of propaganda and mechanisms of influencing had influenced the development of models on the effects of mass communication such as that described by the hypodermic theory, also called "bullet theory" or "theory of magic bullet", that moving inside a vision mechanistic elementary and started from the assumption that being uniform the repertoire of behavioral responses of man, messages could be incorporated in the same way by all the people that were the audience and that the replies to messages were immediate and direct [28].

In this case the persuasive communication has the capacity to strike and influence the decisions of a group of persons perceived as an aggregate of isolated individuals, weak and helpless in the face of the force and the precision of the persuasive communication. According to this theory the hypodermic "each individual is an isolated atom which reacts by only orders and suggestions of the means of mass communication. According to this theory the hypodermic" each individual is an isolated atom which reacts by only orders and suggestions of the means of mass communication cornered" 10 in this case if the messages can reach individuals of earth, persuasion would be easily «inoculated»; i.e.

${ }^{10}$ (Wright Mills, 1963, 203). 
if the «target» was reached, it would have been the success that it was intended. ${ }^{11}$

This general confidence on the power of the mass media derived from the results of the warmongering in act during the Great War [29]. It was thought then that the media could shape public opinion and influence the masses in favor of any point of view. ${ }^{12}$ The bullett theory has had a lot of success, especially in its application to the communicative phenomena as specific as the electoral campaigns or, precisely, advertising and, despite the research on the effects they have then widely shown the limitations, remains surprising its survival, sometimes still current, as diagram appropriate analytical, especially in advertising. ${ }^{13}$

The Theory of limited effect and the theory of the agenda setting: According to the theory of limited effects of media interest to acquire in-formation, as well as the exposure, the perception and storage of a message occur according to processes selective for which, "...the components of the audience tend to expose themselves to information congenial to their attitudes and to avoid messages that are instead different" [30]. In this case the campaigns of persuasion, have success especially with individuals who are already agree with the views presented or which are already sensitized to the proposed themes. These are precisely the individuals most interested in a topic those exposing themselves to the message, while others, in our case of individuals most at risk would be resistant to such exposure. The way to study the processes of persuasive must therefore take in consideration that the functions of the mind can no longer be conceived as operations of a Cartesian machine computational or, detached from the purposes for which exist, namely to serve the practices required for the interaction of interpersonal relations.

This means that we must learn to see the human mind and all psychic processes that underlie our behaviour as a meeting point for a wide range of influences structuring agents, whose nature can be shown only on a canvas wider than that provided by the study of the individual bodies by proposing a way to analyses concepts such as perception, attention, decision, motivation in relation to the processes of signification influenced and [31] determinants from the cultural and social context, from interpersonal net in which one is immersed and the meanings mediated by communication channels. ${ }^{1415}$

According to this theory, "people tend to include or exclude from their knowledge of what the media include or exclude from their content [32]. The public also tends to assign to what it includes, an importance that reflects from near the emphasis given by the mass media events, issues, people". ${ }^{16}$ The media, in the perspective of agenda setting, indicate what information and news to which we must pay more attention and what is their relative importance in a given time. ${ }^{17}$ In this case the media do not say as subjects must think but what to think. The general idea of a correspondence between agenda of the means of communication and that of the audience was first investigated experimentally by McCombs and Shaw [33].

The methods used to make the news more meaningful and affect the representation that the listener is a particular issue or phenomenon are many: the frequent repetition of the news; the temporal continuity of presentation; the space given to the news and the order with respect to the other news; the importance of the header and the specific communicators who give news; rhetorical aspects such as for example the capable [34]. Try of emotionally involve the audience, the presentation of news with moves or other media knowing that the move offers dignity and value to the news, the use of comments that generalize the contents of a single fact or episode. ${ }^{18}$

This phenomenon is persuasive, definable such as flu and determines the way to see and interpret a phenomenon, is closely connected to the heuristic mechanism of availability, according which must estimate the numerosity of a category or the probability of occurrence of a phenomenon or even the judgement of persons will be influenced by information more available or readily available in memory. In the case of agenda setting some information are more available because presented with greater frequency or pregnancy, making this information the most immediate and available [35]. The recognition of the relationship between the agenda setting and the heuristics of availability allows to overcome that vision linear deterministic and that the first expression of the theory he brought with him.

The presence of a heuristic mechanism implies a mediation of the cognitive processes in the relationship between message, understanding of the content of the message and persuasive effect [36]. One of the greatest limitations of a known theory on the effect of mass communication on the construction of social representations, the theory of agenda setting, is precisely that it does not consider the semantic components own message and existing structures of knowledge of the individual listener.

\footnotetext{
${ }^{11}$ (Wolf, 1985, DeFleur, Ball-Rokeach, 1989)

${ }^{12}$ (De Fleur, Ball-Rokeach, 1989)

${ }^{13}$ (Wolf, 1985)

${ }^{14}$ (Meccaci, 1999)

${ }^{15}$ (Harrè, 1994)

${ }^{16}$ (Shaw, 1979, p.96)

${ }^{17}$ (McCombs and Shaw, 1993).

${ }^{18}$ (McCombs and Gilbert, 1986).
} 
The Theory of cultivation: Unlike the theory of agenda setting that refers to the cultivation not only provides that the media tell us what are the things on which to decide and to think about, but also and especially in that way we must think about them. According to the theory of cultivation of the mass media have a role in the socialization able to shape the perceptions and attitudes, values, decisions and behavior [37].

The means of mass communication are considered as rulers' environment symbolic of modern life, inside of this explanatory model of persuasive processes the term ${ }^{19}$ mainstreaming refers to the process through which the television viewing leads to a homogenizing in conceptions of the world. This vision is born from a comparison of social representations and visions between people who make extensive use of television and of those who on the contrary watch rarely television. One of the main criticisms that is moved by this theory relates to the nature correlation results on which it relies [38]. Not having precise information on the directionality of the report from the vision's perceptions, there demonstrates that the group sees more television has been influenced necessarily the contents of this. The report could be perfect- Inverse mind. Also, referring to the theory of roles, to be persuasive we must produce a message that matches as closely as possible with the other you envision us with what you expect from us, with what is contained at the level of expectations in the social situation in which you exercise the communication. ${ }^{20}$

\section{The study of the individual elements persuasive}

Of great interest was not only the discovery of the effectiveness of the source but also relief that the credibility of the source itself, at equal content of massage, had no immediate effects on the process of understanding, while influenced the change of attitude, even if the effect was of short duration. Kelman and Hovland (1953) called this latent effect, thinking that the subjects after a certain period they tend to forget the characteristics and the identity of the source of the message. According to the authors with the elapse of time tends to dissociate source from content [39].

Of great interest was not only the discovery of the effectiveness of the source but also relief that the credibility of the source itself, at equal content of massage, had no immediate effects on the process of understanding, while influenced the change of attitude, even if the effect was of short duration. Kelman and Hovland (1953) called this latent effect, thinking that the subjects after a certain period they tend to forget the characteristics and the identity of the source of the message. According to the authors with the elapse of time tends to dissociate source from content [40].
This is a field of analysis processes persuasive that is developing in a significant manner also for obvious reasons the historical, cultural and economic: the proceeding of the crisis of the welfare state, the development of a commitment always more articulated in the area of discomfort by the increasingly numerous structures of non-profit but mainly the growth of a greater social commitment staff in voluntary activities, not more closely tied to that civic and social of collective societies, but rather is related to the need more specifically an individual undertaking considered first of all staff (feel good helping others) and only subsequently intended to meet a social need and community. ${ }^{21}$

The social communication has become an interesting field of study and analysis of the processes of persuasion [41]. However, despite several studies have offered interesting indications to make more effective the traps in this context, these are often disregarded. Suffice it to think of the communication policies in the field of safety at work or on the road safety to rediscover discover that many messages obtained results contrary to their intentions. In addition to the simple repetition of the message that is linked to the importance of the heuristics of availability, a persuasive message should not rely to tension and fear, but rather to emphasize positive results associated with change of a behaviour.

The reference to fear in this context of communication is linked to the theme that often this characterizes type of communication and is sometimes used without thinking about the effects that might have in generating perceptual defenses rather than draw attention. Also, a message of this type is even more persuasive if it can push the audience to communicate, share and discuss the issue with other people. The principle according to which the discussion of a message and its defense during a dialectical confrontation with other facilitates the adoption of the choices and behaviors listed in the message [42]. This is a theme that has been studied and deepened by Leon Festinger ${ }^{22}$ (1957) and from the theory of cognitive dissonance.

The contribution offered by Festinger makes it increasingly shared the idea according to which the effectiveness of the message on the decision-making processes and behavior cannot be assessed in absolute, considering its arguments, the source credible, organization of content, but must be considered in relation to its ability to reduce a situation of discomfort, like the dissonance.

The cognitive dissonance, which stems from the contrast between an attitude and behavior or between two attitudes, produces a condition of discomfort that pushes the individual to take all possible solutions to create a state of coherence, balance and consequently of "wealth". According to this theory, if a person

\footnotetext{
${ }^{19}$ (Gerbner et al. 1980, p. 14)

${ }^{20}$ [Bellen- ger].

${ }^{21}$ (Siri, 2001; Fabris, 2003)

${ }^{22}$ (Parrot, Monahan et al. 1998)
} 
is Acting some behaviors or to declare certain opinions contrary to their own attitudes or beliefs, try a state of tension unpleasant due to the dissonance between their behavior or opinion expressed and its attitude [43].

As demonstrated by studies of Festinger this form of dissonance will be perceived if the behaviours or inconsistent views were dictated by free choice or if people were induced to believe that their choices have been done autonomously. If there is an external force which forces acting autonomously is more difficult to justify to themselves and to others a behaviour inconsistent, especially in a social and historical context which makes the consistency and non-contradiction a lifestyle accepted and legitimate.

\section{The economic literature rational in comparison with the development of Marketing}

The assumptions at the basis of economic thought traditional are the rationality in the decisions of the individual and personal interest [44]. The same who theorized hoped to develop an analysis on the pleasure that could explain the main characteristics of human desires starting from the concept of instrumental rationality but not have deepened with further studies of this idea. In instrumental rationality, agents use all the available information to make the best choice among the possible alternatives and welldefined, considering the objectives and calculating to perfection the consequences of the decision taken.

The protagonists of the above model have their own systems of preferences on alternatives themselves and can form expectations, even probabilistic, about the effects of their act. In conditions of certainty, the individual economic maximizes its subjective utility while in situations of uncertainty optimizes than expected. The contribution offered by the economic literature seems somewhat incomplete and unrealistic and this has been pointed out in the first place by the cognitive psychology that not settles for the rational explanations of human behavioral, has begun to investigate the ability of the mind in the act of coding and processing a decision-making process [45]. Thanks to several studies in this field, you are examined other factors which govern the choices and involving not only the rational aspect but also the unconscious: the perception, memory, emotions, beliefs, attitudes are all behavioral evidence that represent systematic deviations to the economical choice rational.

The same Tversky and Kahneman stated: "does not seem to be possible to construct a theory of choice that both together normatively accepted and descriptively adequate". Many are the faults to the above formulation that have ${ }^{23}$ already been identified in the previous chapter: the paradox of Allais, the endowment effect, the preference reversal, the law of small numbers, the effect of mental accounts, the heuristics but mainly the Prospect Theory. Nowadays these violations are deeply analyzed and considered in the literature of marketing because new ones are the guidelines to follow, new the bases on which to design and implement a strategic planning, new consumers and new the needs.

The types and quantities of products manufactured are studied in relation to consumption. The Marketing becomes a way of thinking, a style of corporate life that tries to keep under control the whole system. Does not concern the study and the formulation of axioms, the establishment of models without check what happens in reality but a genuine new mentality which is predisposed to understand the needs and the expectations of consumers and is concerned about how to meet them.

It is a constant work that which engages the companies that develop such policies as the passage from the point of view of the producer to the consumer involves much more detailed analysis of the psychology of the customer and his way of perceiving and evaluate companies, of the motives which impel to choose an undertaking with respect to another or a product rather than others, without counting the difficulty of intercept as these behaviors, ways to hear and perceive themselves and the environment change and evolve over time, depending on the circumstances and from place to place [46].

The protagonists of the marketing process are two: the company at the moment in which it proposes to make an offer to a customer which he knows or assumes to know the purchasing behaviour and the consumer because it manifests the needs and expectations, whose origins can be the lack organic, the psychological state determined socially and culturally or clarification of the desires that generate voltage until they are satisfied.

Both protagonists seek to build up and consolidate a relationship of fidelity that for the company translates into high profitability in a time horizon expanded and for the consumer, in satisfaction of their own needs and expectations. The Marketing is a business function of vital importance precisely because it combines production, technology and society: for this reason, the commitment in the social dimension is fundamental for the connection between the well-being of the individual and collective well-being. It is necessary at this point to clarify the basic concepts of need and desire, from which flows the act of consumption become complex and difficult to interpret and from which develops the entire strategic planning process supported by the function of Marketing [47]. The first is a sense of inner lack that creates a voltage that pushes the individual to put in place a specific behaviour to placard: from unwell then reaches a state of health. It is linked to the aspects inherent and is one of the elements in triggering the purchase process.

The second, namely the desire, is a necessity of a higher order, a need acquired, learned and interpreted, which no longer depends on physiological aspects and primary for the existence of the individual, but from culture, lifestyles, passions and interests, from the values and beliefs. According Henault (1973)

\footnotetext{
${ }^{23}$ (Motterlini and Guala, 2005, p. 14)
} 
"The objective of the Marketing is to transform a need in desire to purchase the product".

All the factors listed first go to influence the choices of purchase by eliminating the concepts on the value inherent in the product and on the utility that it has the capacity to learn. There are no longer any theories according to which the quality of the products offered by businesses is equal and therefore the buying decisions fall on discriminatory pricing, there is not only the rationality as needle of the balance at the moment in which you generalize preferences, there are full and transparent information for market operators: all the basic assumptions of the formulations axioms of currents of economic thought Classic and Neoclassic forgiveness of importance, indeed, are rendered even more unacceptable in the face of the experience of marketing [48].

The latter broadens the vision highly restrictive of the traditional postulates and replaces the figure of homo economics a new subject, the consumer/customer/host, which acts according to motivation also not rational and emotional. For this reason, the behavior of consumption is now seen as a continuum that intersects two realities lived in a manner antithetical: rationality and irrationality/ emotions. To better express this concept, it is good to introduce the classification of Maslow that detects a hierarchical organization of the needs of individuals. The modern subject search emotions and pleasures through the senses, the personal welfare (hedonism), attempts to speak at the individual level and to exploit its capacity (development of itself), to adapt rapidly to the environment highly changeable (plasticity), ${ }^{24}$ Seeks involvement of soul and body and the risk (vitality), gives importance to contacts and relations, to globalization (connectivity), ensures respect for justice, integrity, authenticity of meanings (ethics) and feels the need of identity, to find their roots, origins, to reconstruct its history (membership).

The consumption in this context assumes a new status: is a moment of encounter between the consumer and the producer and between consumers which enhance the experiences and universes of meanings accrued within the complex social systems, it means learning syntax and different grammars in which everyone tries to express himself, to speak for itself with a language well distinct but not very easy to understand [49].

\section{New scenarios between Economic, Marketing and psy- chology}

Understand normal people": this is, according to Colin Camerer (2003), one of the greatest challenges of economic research contemporary. If the exhortation may sound obvious to the ear of the profane, this is not for economists who traditionally have moved within a theoretical framework close to idealizations, rather than to normality. Actor of economic model's standard is in fact a subject ideal-typical, the representative agent, which is believed to be summed up in himself the relevant characteristics of all individuals operating in the market. In simple terms, refer to abstraction of the representative agent - also known as homoeconomics-means to calibrate the theory does not how people are, but rather on how the only individual ideal is taken as a reference. This conceptual operation pursues the objective of simplifying the analysis and assumes that abstract from the subjectivity and imperfections of the individual not remove meaning to search results. The great revolution that the new relationship between economics and psychology are helping to generate stems from the flaws of this hypothesis [50].

Many economists today do not seek more to understand what would choose or as would a fictitious subject, but rather are concerned to understand why human beings in their complexity, finiteness and reciprocal difference, behave in certain-and observable-ways. To proceed in this direction, on the one hand, the economy is open to interaction with other fields of study, with the psychology and neurosciences; on the other hand, economists have developed a rigorous analysis work on the field, which is based on the direct observation of behavior in controlled experiments. ${ }^{25}$

The experimental activity typical of psychology but now widespread also in economic research, does not change the basic problem: develop a theory able to interpret the vast amount of data obtained in laboratory situations that see interact human beings (and not abstract subjects). The Nobel Prize for economics awarded in 2002 at the psychologist Daniel Kahneman research toward a key aspect, represented by the operation of the mind. In his inaugural, Kahneman poses to the foundation of the discourse on the behavior of the agents the understanding of the mechanisms of their reasoning, welding in an unequivocal way the link between mind and economy. This link, on the other hand, is already present in the work of some important economists of the past. ${ }^{26}$

The work of Simon in the second half of the twentieth century have done creak this representation of hypertrophic rationality and superhuman, highlighting the limits. Amartya Sen has defined idiots' rational agents with computational and logical abilities, but poor in any other psychic mechanism. The development of relations between the economy, psychology and neuroscience in recent years have allowed us to take a further step, highlighting that the rationality is only one of the modes that the mind must operate, able to explain, alone, a very small portion of behaviors. Rather, if the economy needs to represent in their theoretical spectrum the thought processes of individuals, cannot be

\footnotetext{
${ }^{24}$ Neuroplasticity

${ }^{25}$ (Novarese Rizzello, 2004; Handbook of contemporary behavioral economics, 2006)

${ }^{26}$ Among whom Alfred Marshall, Friedrich August von Hayek, Thorstein B. Veblen, Carl Menger, Kenneth Boulding, George Lennox Sharman Shackle and Herbert Simon, although only in the last Twenty years has been rediscovered and appreciated by the research program of the cognitive economy Or behavioral economics (Cognitive Economics, 2004). 


\section{Psychology and Behavioral Science International Journal}

limited to a representation simplistic and reductionist of mental functioning [51].

It needs instead of putting at the foundation of their models a cognitive architecture rich, which considers explicitly motivations, of beliefs, desires and goals that the subject has with respect to himself and to others. The acquisition of this awareness changing the research program of the economists in various directions, ranging from the need of a comparison with other disciplines to the redefinition of its object of study, to a transformation of the objectives to be pursued to a change in the instruments used.

The cognitive sciences suggest that to understand the behavior of individuals is necessary to include their mental representations in the plant of the theory. For economists attentive to this message, the link between mental representations and behavior does not constitute an absolute novelty. In a such environment, human beings are guided by its own mental representations in a double sense: since the objectives and actions undertaken to pursue them are affected by the content and the format of the representations; and because their behavior is directed to the results that they are represented in the mind. A line of contiguous research concerns the tendency of human beings to take shortcuts (routine) during their thought processes (mainly in the form of mental representations simplified). This is a theme that Simon had already introduced in the Fifties, the analysis of which now uses skills and tools of investigation new.

The progress of research in this context follow mainly two directions. On the one hand, recourse to shortcuts no longer seen only as a symptom of the limitations intrinsic to the resources human cognitive. On the contrary, it is interpreted as an expression of the adaptive capacity of mind which allows individuals to manage the complexity of the physical and social environment in which they live by simplifying certain aspects. ${ }^{27}$ The cognitive psychologists have highlighted how the tendency of mental processes to become automatic is much more general and pervasive. In a brilliant article refers to ${ }^{28}$ an 'untenable automatism of the Be" precisely to describe how much of the mental life is in fact guided by customs and involuntary mechanisms which fall outside our control. This strand of analysis has a lot of affinity with the debate on the unconscious knowledge - and therefore silence - that has aroused the interest of economists from the contributions of Karl Polanyi in the last century and which today involves scholars from areas different theoretical, with applications ranging from the processes decision-making, the nature of innovation, the transfer of technologies, the organizational processes, the theory of the institutions. The literature of recent years includes various attempts to widen the perspective on the theme.

While traditionally economists have restricted the concept of motivation to the incentives of a financial character, has given way to the idea that it is necessary to consider also aims of nature no material such as for example the need of social consideration, the intrinsic interest for certain tasks, the pleasure of reciprocity in trade, the desire to have no regrets and others. ${ }^{29}$ The other aspect certainly significant concerns the imagination and its links with the processes of innovation and creativity. The research work on the imagination in socio-economic contexts involves issues related to the source of innovation, at the origin of the entrepreneurial spirit, the ability to develop new solutions to solve problems, to the possibility to disengage from the logical and decision-making.

Above all, it invests the possibility for individuals to imagine the situations in a different way from how they are in that moment, thus bypassing the fact of reality and by accessing the possibility of modifying it: Imagination is essential to change. In the literature contemporary economic argument is still underdeveloped, although the materials from which to begin a more thorough analysis are numerous. In these contributions, imagination is defined as the ability of the human mind to produce representations that are not limited to retract the reality, but can amplifying, deforming it or transform it through the contribution more or less ${ }^{30}$ aware of the subject thinking. The ingredients of the imaginative processes are the current perceptions of the individual and those who have settled in its memory, in the form of simple perceptions or as more elaborate of thoughts, events and associations between ideas.

A particularly important characteristic of images lies in their open structure which makes them defined but at the same time capable of change. It is possible to change the image whether changes the meaning attributed to the perceptions and/or to the memories, both if you modify the emotional states/affective of the individual with respect to what it perceives or retrieves from memory. In this perspective, your emotionality acquires roles until a few years ago totally neglected by the literature. In an attempt declared to assimilate the economy to an exact science, economic theory orthodox has moved in a theoretical horizon abstract, in which predominate mechanisms of decision/ behavior purely logical and formalize in mathematical terms. Economists have traditionally excluded the emotions from their field of investigation.

\footnotetext{
${ }^{27}$ This line of research developed mainly by Gerd Gigerenzer and collaborators

${ }^{28}$ (Todd Gigerenzer, 2003), availed of contamination between economics and psychology evolutionist John A. Bargh and Tanya L. Chartrand (The unbearable automaticity of being, "The American psychologist", 1999, 54, 7, pp. 462-79)

${ }^{29}$ (Fehr, Falk 2002).

${ }^{30}$ The authors of the first floor which Adam Smith, Marshall, Edith Penrose, Boulding, Shackle, Simon, James March And Cornelius Castoriadis we have bequeathed to dense contributions of suggestions. Attempts to update the thought of Boulding Castoriadis and, in the light of the developments that have been obtained in the context of psychological, have up to now focused on the theory of decision and coordination processes Patalano ( 2005), the analysis of the institutions and the relationship with the change Patalano (2007).
} 
The first line of research has ${ }^{31}$ produced models in which the variable emotional> are added to the model of traditional choice, without modifying the structure of the bottom. According to this line of study individuals have a only a cognitive instrument, rationality and emotions influences the choices through the benefits and/or the costs involved (in more precise terms, the emotions become an additional variable of the utility function).On the one hand, therefore, emotional states fall within the control of the logic of the decider, on the other hand, the concept of emotion remained undefined, spacing, depending on the circumstances and authors, their feelings, the sense of identity to the instincts visceral. This line of research is the undoubted merit to have reopened the debate on a topic long neglected by the literature through authoritative contributions.

However, it has been the object of criticism by psychologists but also of some economists, dissatisfied with the approach costs/benefits to emotional variables, as well as an analysis that proceeds without a more general view of the mind and of its operating mechanisms. ${ }^{32}$ Hanoch (2002) emphasized as the emotional dynamics are equipped with its own internal logic which directs the behavior of the agents together with the processes of rational reflection, not already in antithesis to them. In decision-making processes emotions play two main roles, both involved in the management of the information that the subject receives from itself and from the environment in which they live: they contribute to setting the priorities of the individual and orient his attention.

With respect to the first point of emotional states affect the hierarchy of objectives to be pursued, helping to establish the gradations of importance: identifying what counts the most and that therefore becomes indispensable in the mental representations of the subject, depends to a large extent by considerations involving the emotions and affections. The influence of emotions on the order of priority between the objects is particularly evident in conditions of danger when, for example, the objective of survival takes precedence over all other, but involves more general in everyday life.

Secondly, the emotions they induce the subject to focus on certain aspects of reality, to the exclusion of others. In this sense they select the information and the main elements on which to focus, helping to define a way to see specific, and subjective. For example, in a context of decision-making in which there are several alternatives to choose from, the sentiments concur to identify what parameters taken into consideration to evaluate alternatives available and which give greater weight, thus defining the register 'dei thoughts and desires'. In the context of psychological, research has produced a vast amount of experimental work on the mechanisms through which the emotions become a source of information and help the subject in the processes of attribution of value. Applications to the economy are potentially very large and in part have already begun to develop. ${ }^{33}$

\section{Experiential Marketing, Emotional Marketing and the perception of reality and metaphors}

Products as well as the brand, are purchased for the values that derive from the synergy of size functional, ergonomic and aesthetic qualities and for the symbolic meanings that they transmit. Shopping today is no longer an activity as an end but is a component that falls in the overall assessment of the experience about a particular brand or product. The places of consumption, rich in stimuli and information, assume a valence ritual and shopping is then lived as an experience which can activate our involvement by the sensorial perception and emotional of products and services.

From these evidences, it will thus be understood that the experience assumes a role of primary importance in marketing strategies. The experiential marketing describes the experience as the moment higher connection between the stimuli coming from the outside world and the inferiority of the subject represented by the subjective component of the memory and of memories, and it is precisely in this situation that marketing must intervene to obtain an emotional involvement (engagement) with the consumer. The experience of the consumer becomes an important variable for the formulation of the purchasing decisions of the latter, as aspects of multi-sensorial places of consumption play a key role in the decision-making process of the consumer.

The brand must involve and entertain the consumer through the creation of special situations or events that make the experience of the world of brand unforgettable and unique. From the analysis of the behavior of consumption it is possible to obtain then valuable information, the perception of tactile stimuli, auditory olfactory, gustatory, and especially visual, plays an essential role in understanding and in the study of the behavior of consumers.

Being the consumption a mode of expression of oneself within a social sphere and both on the individual level, through the affirmation of their own identity, it can be identified as an emotional experience: the emotion that springs from an experience, if relevant, can be transformed into a somatic marker able to settle in the memory of the individual the positive association established between the emotional experience and the brand.

Just over two thousand years the emotional marketing is considered a discipline of reference, concomitantly with the birth

\footnotetext{
${ }^{31}$ Developed from the work of George A. Akerlof and Rachel E. Kranton (2000),
}

Mathew Rabin (2002), Jean Tirole (2002)

${ }^{32}$ Castelfranchi ( 2003).

${ }^{33}$ (For an excellent critical review, v. Pham 2007) 
of the neuro-marketing, i.e. of the use of new technologies for measuring brain activity which allow to have a representation, thanks to the physiological changes such areas activated in the brain by a given stimulus (for example The emotional marketing can be defined as the set of numerous facets of marketing unconventional flourished in recent years (guerrilla, tribal, green or web) joined to the new technologies of measurement provided by the neuro-marketing ${ }^{34}$.

The emotions play an extremely important role in the choice of what we store in our memory. The objective of the emotional marketing is precisely to emphasize the role of emotions in the creation of events or situations linked to a brand, in such a way as to be able to fix the remembrance of the latter in the memory of the consumer. The focus of this strategy is to exploit the association that is created between the emotional impact of the event and the brand or product. If the memory of lived experience is positive, we have therefore a positive attitude even in respect of that brand or product [52].

Working on the emotions and the boundaries of marketing will expand to include disciplines that do not fall within the economic area such as the Neuroscience and cognitive psychology, sociology, philosophy. Dealing of man and its interactions with the environment outside these disciplines, in collaboration with the marketing, allow you to have a thorough knowledge of the behavior of the individual as a consumer, in a new perspective more realistic and practical.

The marketing by placing the consumer at the center of its own strategies cannot rescind from these fields of study, as the individual-consumer is not an economic agent that takes decisions in a rational way based solely on cost-utility, but is in reality an individual that interacts with the external environment (by means of the senses and the body) and which deals with it developing strategies and decisions are influenced by emotions, the perceptions and the sensations. To be able to study the consumers to guess the outcome of the decision-making processes of purchase, you must understand how they interact with the environment that surrounds them, in other words to understand how consumers/individuals perceive reality.

Marketing communications aimed at potential consumers, are designed with the aim of making captivating messages and immersive, to attract their attention. Understand what is perceived by the consumer is thus an aspect of primary importance since often the message conveyed is subject to different interpretations from those for which it was designed. The perception of marketing content is processed by the individual as any other stimulus belonging to the outside environment, therefore the study of the mechanisms that allow a subject to interact with an external stimulus is essential for a more thorough analysis of the consumer.
Developments in neuro-scientific demonstrate that individuals do not perceive the reality in the same forms of which it is composed, because the brain does not reproduce. The shapes of reality as they are, but through processing of visual representations, codifying interactively brain models of timespace of external reality. Our brain and our memories system work for semantic associations: a stimulus any is able in fact to emerge from the memory of long period a memory stored which we consider to be inherent with the stimulus in question. We can therefore say that individuals are able to construct an interpretation of reality subjective, usually linked to our past experiences. This phenomenon occurs in our mind in a temporal arc extremely reduced and being bonded by means of an appeal to the memories from the memory of long period to personal content and subjective, is a possible generator of emotions. What contributes to activate this process is first and foremost the perception of the stimulus that belongs to the external reality, followed by creativity that, through such an association gives a narrative sense and meaning to the stimulus itself.

The experience gained from the individual acquires, therefore, a meaning that goes beyond the stimulus perceived, the correspondence of subjective meanings which is generated by the memories enriches and gives depth to the experience ${ }^{35}$. By analyzing the mechanisms that are activated through the perception of the stimuli, it is possible to highlight two interesting aspects that must be considered in the design of the contents of the messages addressed to the consumer: The first concerns the functioning of the brain through semantic procedures and not through linear processes adjusted according to rational logic.

The brain is in fact able to work on multiple systems simultaneously, managing parallel processes and interrelated that occur in an automatic manner and produces mental models that currency, compare and choose to run outside of our conscious control. The second aspect concerns the role of emotions. The emotions, relating to immersive experiences and unforgettable assume a key function in settle the lived experience in our minds, they in fact create an imaginary bridge between the external reality and the subjective experiences and that are stored in our mind as memories and images that make up our experiential heritage. Because of the enormous variety of the offer and the corresponding media confusion, consumers to evaluate and implement the buying decisions often rely on the experience of past consumption, but what results to be decisive in the choices of purchase is the content of the transmitted message, its ease of understanding and its significance.

The messages conveyed by the companies must be able to communicate with the receiver at a deep level: "The contents of a message must be relevant, i.e. must touch the chords of

${ }^{34}$ (Gallucci, 2011)

${ }^{35}$ (Morin, 1993) 
deep sensitivity of people". The emotional involvement, i.e. the engagement, allows you to establish a harmony between the consumer and the content of the message by creating an empathy with the brand or with advertising based on values and meanings that belong to a symbolic dimension, thereby establishing a relationship between the parties that goes well beyond the simple product purchase [53].

From the contribution of neuroscience, it is known that the choices made by individuals take shape in the unconscious dimension and that the contribution of the rational component affects only a minimal part: the choices in fact, maturing below the levels of awareness, guide consumers in the implementation of behaviors closely related to their previous experiences and to what the leaders of communication define the values of the brand. Thus, comprise as the brand and the respective communications are perceived by consumers is essential for the formulation of marketing strategies aimed at creating an emotional involvement with the consumer.

Whereas most of the mental activities occur in a manner unconscious and therefore unaware it is not possible to obtain this important information from the verbal responses of consumers, but you must use methodologies capable of meeting the hidden knowledge of these latter. One of the methods that according to the literature can elicit the unconscious knowledge is the one that uses the conceptual metaphors devised by Gerald Zaltman. According to the author through metaphors marketing can arrive to acquire information about the thoughts of consumers, not obtainable from the verbal responses and aware of the latter. To understand how companies can use of metaphors to satisfy the deepest desires of the consumer, it is necessary to understand the logic underlying the cognitive thought and activities unconscious that guide individuals in the interpretation of the contents. It is thanks to the cognitive processes that individuals develop and formulate verbal language, not the contrary.

The author ${ }^{36}$ considers the language in a multidimensional approach that includes in addition to verbal communication, other communication channels such as gestures, the speech intonation, the body posture, touch, eye contact, the sense of time; the thought is then constructed based on "image" that the mind creates through the perception of visual stimuli, gustatory olfactory, etc. The metaphors being linked to the imagination, guide the individual in the interpretation of the outside world through images that the mind constructs in relation to stimuli perceived by sensorial channels. The metaphors being linked to the imagination, guide the individual in the interpretation of the outside world through images that the mind constructs in relation to stimuli perceived by sensorial channels. The use of metaphors in language can be described as the final part of a complex functional architecture in which processes sensory and cognitive functions, always considered separated, interact and collaborate for the construction of sense.

The Metaphor acts as a bridge between the cognitive thought and subjective experience, in other words allows a conceptual representation of the subjective experience and abstract in concrete terms and family. Thanks to the metaphors we can transfer knowledge from a concrete concept and known to one abstract and difficult to represent in other ways. In marketing the metaphor is a valuable tool because it allows you to create a conceptual correspondence between the product, the values of the brand and the desires of the consumer due to its nature allusive.

Zaltman was the first to transfer the conceptual metaphors in marketing by using them as a means of identifying the thoughts and the unconscious feelings of consumers because they "direct the attention of the consumer", it will affect the perceptions, make him capable of conferring a sense of what it finds, affect its decisions and its actions. "The metaphor of the connection refers to a sense of belonging or exclusion, that of resource instead may represent tangible or intangible which sustain us in difficult periods, while the key control (or lack thereof) to describe when things we "escape ${ }^{37 "}$ and finally the metaphor of transformation that covers the stages of change and the periods of our life. The marketing must therefore understand what happens in the mind of consumers to be able to satisfy the desires that belong to the unconscious sphere. The interpretation of metaphors in fact, allows to overcome the distance between the word and the meaning, bringing to light the thoughts and deep emotions of consumers.

\section{Basic terms and definitions}

\section{Agenda setting}

Indicates what information is contained in the message to which we must pay more attention and what is their relative importance in a given time. The implementation strategy consists in frequent repetition of the message, the temporal continuity of the presentation, the space given to the type of information and the order with respect to other information.

\section{Bullet Theory}

This theory assumes that being uniform the repertoire of behavioral responses of man, messages could be incorporated in the same way by all the people who constitute the audience. In this way the persuasive communication can influence the decisions of the group. This theory treats each individual atom isolated that reacts by only orders and suggestions of the means of mass communications. who monopolize.

\section{Cognitive change}

This does not necessarily involve a change in behavior. The main aim is to create awareness and knowledge by providing adequate information to facilitate the process of persuasive.

\footnotetext{
${ }^{36}$ (Zaltman, 2003)

${ }^{37}$ (Lackoff e Johnson, 1980).
} 


\section{Change of action}

Consists in inducing a certain number of people to perform certain actions. The feasibility of this change is based on the effectiveness of motivational information according to which individuals will be forced to perform a specific action.

\section{Latent effect}

it is based on the principle that the subject after a certain period they tend to forget the characteristics and the identity of the source of the message. According to the authors (Kelman and Hovland) This involved not immediate effects on the process of understanding of the message, but influenced the change of attitude, even if the effect was of short duration.

\section{Heuristic processing}

Is a cognitive process that uses cognitive structures claims, expectations, beliefs, opinions and prejudices that a subject considers in the decision-making phase? In this case we refer to automatic processes that are typically those that are activated more frequently when an individual makes a choice.

\section{Neuromarketing}

Thanks to instruments scientific-neuro and biometric, it is possible to obtain information more objective and precise with respect to traditional methods, to understand the attitudes, beliefs, the views and the perceptions of consumers on the proposed contents by companies. The neuro-marketing provides for the use of the techniques of brain imaging to identify areas of brain related to psychological phenomena such as: cognitive activities, thoughts, emotions, sensations and perceptions considered in their biological dimension, i.e. pure chemical activations and neural.

\section{The principle of consistency}

binding the individual to be consistent with the values and principles that had internalized and that had to be able to translate into behavior congruent, even in the absence of a social context that can support these models of values. As is known, the behavior does not have its contrary (you cannot do not behave) and then, in the face of a problematic situation in some way it acts in one direction rather than the other, the becoming of the events.

\section{The theory of limited effects}

According to this theory, the interest of the media to acquire information, as well as the exposure, the perception and storage of a message occur according to processes selective for which the members of the audience tend to expose themselves to information congenial to their attitudes and to avoid messages that are different.

\section{The theory of cognitive response}

analyze the conditions that occur when there is the active participation of the subject to the process of persuasion. The tactic of persuasion is effective when directs and channelizes the decisions so that the receiver of the Message reflects on the issue with the same point of view the communicator: contact with a subject to persuade must not be generic.

\section{Conclusion}

The new relationships between the economy, Marketing and psychology are causing significant changes. Change the variables of economic theory: the mind becomes a sort of intermediate variable that connects the environment to the subject. To understand the behavior of the individual are trying to shed light on its psychic processes; to understand phenomena complex macroeconomic becomes important to study the interaction conscious among a multiplicity of actors thinking. Change the ratio between the theory and the reality.

Economic theory has traditional regulatory character, i.e.create models that deal with how the reality should be, suppositories valid certain hypotheses. The traditional approach to decisions represents an example rich and consistent benchmark, of ideal representation with respect to which the economist can evaluate every time the observable deviations and designing any corrective intervention approach. The new relationship between economics and psychology contribute to overthrow the logic ideal real-that has just been described: scholars explicitly attempt to describe situations ill-defined and therefore difficult to standardize and precisely for this reason characterized by a unique nature and transient, while the ideal representation remains entirely out and if anything is interpretable as away from reality.

In this new perspective change the instruments of inquiry: the analysis of experimental character becomes important not to lose the loop with reality and that 'normality' that the theory proposes to explain. Especially, change the weight of subjectivity: is less the hypothesis of a single subject ideal typical and burst in theory the heterogeneity of individual behaviors, experiences afterwards, the accumulated experience and knowledge acquired, the ability to learn humanity in short, with its core made of errors, adaptations and compromises. It may seem, and certainly is a profound change in the way of doing theory.

Not without however consequences for what Hayek defined the man on the spot, or for the individual who is in a place any of his everyday life. There is a widespread tendency in society today to represent the economy as modeled by macro forces which we more or fewer slaves, despite their impact on our lives. The precarious situations in the world of work, the fluctuation of grants, the trend of the productivity, the irruption continues the market of new technology are described by the media as 'facts' to be included in the dynamics of things.

In the face of these complex phenomena, the message of the economy that studies the behavior is very clear: there is no economic fact that does not concern individuals and that does not pass for the weft of relations between subjects. The market is not a dark force that draws the future of humanity without involve them; the market is a coordination mechanism, exchange and sharing of choices and representations of the world that the 
individual processes and can change. As long as this possibility confers value.

The ability to elicit an emotional response, by means of an advertisement or other communication tools, is one of the objectives more areas of marketing. However, the complexity of the measurement and quantification of emotions has prevented the study of these phenomena to be part of the economy and of marketing, which for a long time have neglected the emotional component processing models based on the usefulness and the rationality of the individual.

In recent years there have been achieved enormous progress in the study of the functioning of the brain and the relationship between the behavior of the individual and his brain activity. Developments in the field of neuro-scientific have demonstrated that emotions constitute the fundamental basis from which flow the thoughts, behavioral and actions of individuals. These considerations make it therefore clear the importance of the emotional dimension both in decision-making processes of consumers both in measurements of the impact of marketing actions.

To measure the effectiveness of advertising and the messages addressed to consumers, from time are undertaken research aimed at a better understanding of the role of emotions. The neuro-scientific studies have demonstrated that the human mind is not able to understand the mechanisms that regulate their thoughts and their actions, the individual is indeed aware of only a small percentage of what really happens during a decisionmaking process.

Many traditional approaches used in marketing research, are focused on the rationality of individuals and on the processes aware that they can analyses and expose verbally, consequently these methods fail to grasp the mechanisms activated by the emotions that occur under the level of consciousness. To introduce in the marketing research these phenomena it is necessary to explore new approaches, different from those traditionally used to investigate what happens in the mind of the consumer. This thesis is meant to highlight the role of the emotional component within the decision-making processes of the individual consumerand parallel, explore the criticality of the new discipline of neuromarketing. The hope that the Neuroscience can provide more accurate information on consumers than traditional focus groups and the classic market research, has pushed many companies toward the use of new practices of neuro-marketing.

\section{References}

1. Arcuri L, Castles L (1996) The transmission of thoughts, an approach psi- cologico to mass communications, decibels edit rice, Padua.

2. Aspinwall LG, Brunhart SM (1996) Distinguishing optimism from denial: Optimistic beliefs predict attention to health threat. Personality and social psychology Bulletin 22(10): 993-1003.

3. Ajzen Icek (1975) Belief, Attitude, Intention and Behavior: An introduction to theory and research.
4. Barbetta GP (1996) Non-profit. The Mill: Bologna Bauman Zygmunt 2007 Scrap Screw, Publisher Laterza, Italy.

5. Bellenger L (1985) The Persuasion, PUF, Paris, France.

6. Boccacin L (1993) The synergy of the difference. A sociological analysis of the third sector in Italy. Franco Angeli, Milan, Italy.

7. Cacioppo JT, Petty RE (1983) Central and peripherical routes to suesion. In: Percy AL (Ed.), Woodside, advertising and consumer psychology, Lexintong Brooks.

8. Cacioppo JT, Petty RE (1989) Effects of message repetition on argument processing, recall, and persuasion. Basic and Applied Social psychology 10(1): 3-12.

9. Chaiken S (1980) Heuristic versus systematic information processing and the use of source versus message cues persuasion. Journal of personality and social psychology 39(5): 752-766.

10. Caste Franchi Cristiano (2003) Cognitive Anatomy and Functions of Expectations. In: Proceedings of IJCAI 2003 Workshop on Cognitive Modeling of Agents and Multi-Agent Interactions, Acapulco, Mexico, USA, p: 9-11.

11. Gallucci Francesco (2011) Integrated methods for the analysis of consumer behavior. Micro \& Macro Marketing 3: 631-640.

12. Cronkhite G (1969) The persuasion, Communication and change of com-Gait. Franco Angeli, Milano, Italy.

13. DeFleur ML, Ball-Rokeach S (1989) Theories of mass communication ( $5^{\text {th }}$ edn), White Plains, Longman, New York, USA.

14. Edelstein AS (1993) Thinking about the criterion variable in agendasetting research. Journal of communication 43(2-1): 85-99.

15. Fabris Giampaolo (2003) The new consumer: toward the postmodern. Franco Angeli, Milan, Italy.

16. Fishbein M (1975) Belief, Attitude, Intention and Behavior: An introduction to theory and research.

17. Festinger L (1957) A theory of cognitive dissonance. Standford University Press Standford, Trad. It. The theory of cognitive dissonance. Franco Angeli, Milan, Italy.

18. Florentines G (1992) Non-profit organizations and volunteer work.

19. Milan Greenwald AW (1992) New Look 3: Unconscious cognition reclaimed. Am Psychol 47(6): 766-779.

20. Freidlander Frank, Dave Brown L (1974) Organization Development, Annual Review of Psychology 25: 313-341.

21. Gerbner George (1980) Cultivation Theory First published: September.

22. Hafer CL, Reynolds KL, Obertynski MA (1996) Message comprehensibility and persuasion: Effects of complex language in counter attitudinal appeals to laypeople. Social Cognition 14(4): 317-337.

23. Harrè Rom (1994) Lecturer in Philosophy of Science and Fellow Rom Harre. Grant Gillett SAGE.

24. Hovland (1953) Communication and persuasion, New Havens, Yale University Press, USA.

25. Kapferer JN (1983) Tracks of persuasion, the influence of the media and the publicity on behavior. In: Eri, Turin, Kruglanski, AWT Freund (Eds.), The freezing and unfreezing of lay-inferences: effects on impressionable primacy, ethnic stereotyping, and numerical anchoring, Journal of Experimental Social Psychology 19: 448-468.

26. Lackoff George (1980) Metaphors we live by London. The university of Chicago press, USA.

27. Mannetti L (2002) Social Psychology. In: Rome Mantovani G (Ed.), Manual of social psychology. Carocci Publisher, Joints Florence, USA. 
28. Meccacci Luciano (1999) Psychology and Psychoanalysis in Italian culture of the Twentieth Century. Roma-Bari, Laterza, Italy.

29. Mitra Kaushik (1999) In the construction and definition of their value. Journal of Services Marketing 13(3).

30. Morace Francesco (2004) Happy Societies. The death of marketing post-modern and the return of the great values. Books Scheiwiller.

31. Morin CM (1993) Treatment manuals for practitioners. Insomnia: Psychological assessment and management. Guilford Press, New York, USA.

32. McCombs M, Shaw DL (1972) The agenda-setting function of mass media. Public Opinion Qaurterly 36(2): 176-185.

33. McCombs M, Shaw DL (1993) The evolution of agenda-setting research: Twenty-five years in the marketplace of ideas. Journal of communication 43(2): 58-67.

34. McGuire, William J (1985) Attitudes and attitude change, in the Gardner Lindzey and Elliot Aronson. Handbook of Social Psychology, Random Hourse, New York, USA, 2: 233-346.

35. McGuire WJ (1964) Inducing resistance to persuasion. In: Berkowitz (Ed.), Advances in experimental social psychology, Academic Press, USA, 1: 191-229.

36. McGuire WJ (1969) The Nature of attitudes and attitude change. In: Lindzey C, Aronson E (Eds.), the Handbook of Social Psychology, Vol. VIII, Packard V, the occult persuasori, Einaudi, Torino, Italy, p: 26.

37. Monahan Jennifer L (1998) I Don't Know It but I Like You the Influence of Non-conscious Effect on Person Perception. Human Communication Research 24(4): 475-637.

38. Motterlini Matteo (2005) Emotional Economy. Feltrinelli, Italy.

39. Novarese Marco (2004) Experimental Economy. Mondadori, Italy.

40. Petty, Richard E, John T, Cacioppo (1986) The Elaboration Likelihood Model of persuasion. In: Leonard Berkowitz (Edt.), Advances in Experimental Social Psychology 19: 124-181.

41. Petty RE, Cacioppo JT (1983) Addressing disturbing and disturbed consumer behavior: is it necessary to change the way we conduct behavioral science? Journal of marketing research 33: 1-8.

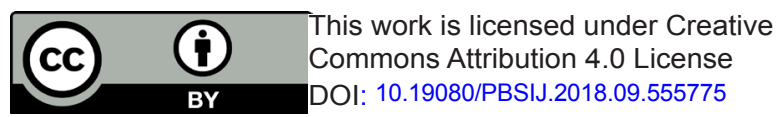

42. Petty RE, Wells GL, Brock T (1976) Distraction can enhance or reduce yielding to propaganda: Thought disruption versus effort justification. Journal of Personality and Social Psychology 34(5): 874-884.

43. Petty RE, John T, Cacioppo, Goldman R (1981) Personal involvement as a determinant of argument-based persuasion. Journal of personality and Social Psychology 41(5): 847-855.

44. Rogers RW, Prectice Dunn S (1998) Protection motivation theory. In: Gochman D (Edt.), Handbook of health behavior research, Plenum, New York, USA, 113-132.

45. Romano D, Il Mulino, Bologna, Russian V, Crescentini A, et al. (2007) Image: marketing and communication "Values and mass media: a model of analysis for the study of processes of communicates ion in Resource Man. Franco Angeli, Milan, Italy.

46. Shaw E (1979) Agenda-Setting and Mass Communication Theory. International Communication Gazette 25(2).

47. Simon HA (1957) A behavioral model of Rational Choice. In: Models of Man. Social and Rational: Mathematical Essay on Human Behavior in a social setting, Wiley, New York, USA.

48. Simon HA (1979) From Substantial to procedural rationality. In: Latsis SJ (Edt.), Method and appraisal in Economics, Cambridge University Press, Cambridge, England.

49. Tesio L (2004) Decide, Raffaello Cortina Editore, Milan, Italy.

50. Tversky A, Kahneman D (1973) Availability: a heuristic for judging frequency and probability. Cognitive psychology 5: 207-232.

51. Wolf M (1985) Theories of mass communications. Bompiani, Milan, Italy.

52. Klapper Joseph T (1963) Mass communication research: an old road resurveyed. Public Opinion Quarterly 27(4-1).

53. Zaltman Gerald (2003) How Customers Think: Essential Insights into the Mind of the Market. Harvard Business School Press, USA.

\section{Your next submission with Juniper Publishers will reach you the below assets}

- Quality Editorial service

- Swift Peer Review

- Reprints availability

- E-prints Service

- Manuscript Podcast for convenient understanding

- Global attainment for your research

- Manuscript accessibility in different formats

( Pdf, E-pub, Full Text, Audio)

- Unceasing customer service

Track the below URL for one-step submission

https://juniperpublishers.com/online-submission.php 